\title{
Excessive daytime sleepiness and migraine: a population-based study
}

\author{
BK Kim ${ }^{1}$, JM Kim², KS Lee ${ }^{3}$, MK Chu ${ }^{*}$ \\ From The European Headache and Migraine Trust International Congress \\ London, UK. 20-23 September 2012
}

\section{Background}

Excessive daytime sleepiness is a common symptom, with a prevalence of $10-20 \%$ in general population and is reported to be with associated with migraine. However, the prevalence, clinical features, and impact of excessive daytime sleepiness among migraneurs in populationbased setting have only rarely been reported.

\section{Objective}

To assess the influence of excessive daytime sleepiness on clinical features and impact of migraine.

\section{Methods}

We selected a stratified random population sample of Koreans over age 19 and evaluated them with a 60 -item semi-structured interview designed to identify headache type using ICHD- 2 criteria. We assessed the Epworth sleepiness scale (ESS) for assessing sleepiness and excessive daytime sleepiness (EDS) was defined as ESS $\geq 10$. We also included items of HIT-6 to assess impact of headache.

\section{Results}

Of 2,836 all participants, 152 (5.1\%) were diagnosed as having migraine. EDS was more prevalent among migraineurs comparing to non-migraine controls $(25.7 \%$ for migraineurs vs. $16.3 \%$ for non-migraine controls, $\mathrm{p}=0.003$ ). Migraineurs with EDS reported higher attack frequency per month (7.0 \pm 9.7 attacks for migraineurs vs. $3.5 \pm 5.8$ for non-migraine controls, $\mathrm{p}<0.000)$, higher VAS score for pain intensity $(7.1 \pm 1.8$ for migraineurs vs. $6.0 \pm 1.9$ for non-migraine controls, $\mathrm{p}=0.006$ ), and higher HIT- 6 score $(60.6 \pm 10.3$ for migraineurs vs. $52.8 \pm 8.3$ for non-migraine controls, $\mathrm{p}<0.000$ ) comparing to migraineurs without EDS. Migraineurs with EDS showed more of depression
$(\mathrm{OR}=5.67,95 \%$ CI 2.5-12.7), insomnia $(\mathrm{OR}=2.98,95 \% \mathrm{CI}$ 1.1-8.4) and sleep disordered breathing (OR=2.78, 95\% CI 1.1-7.3) than migraineurs without EDS. Unilateral pain, pulsating quality, aggravation by routine physical activity, nausea, vomiting, photophobia and phonophopbia were not significant according to EDS.

\section{Conclusions}

EDS is prevalent among migraineurs in general population. Attack frequency, severity and impact by headache increase with EDS.

\section{Author details}

${ }^{1}$ Department of Neurology, Eulji University School of Medicine, Korea, Republic of. ${ }^{2}$ Department of Neurology, Chungnam National University, College of Medicine, Korea, Republic of. ${ }^{3}$ Department of Neurology, Seoul St. Mary's Hospital, The Catholic University of Korea, Korea, Republic of. ${ }^{4}$ Department of Neurology, Hallym University College of Medicine, Korea, Republic of.

Published: 21 February 2013

\section{References}

1. Barbanti P, Fabbrini G, Aurilia C, Vanacore N, Cruccu G: A case-control study on excessive daytime sleepiness in episodic migraine. Cephalalgia 2007, 27(10):1115-9.

2. Ødegård SS, Engstrøm M, Sand T, Stovner L, Zwart JA, Hagen K. Associations between sleep disturbance and primary headaches: The Third Nord-Trøndelag Health Study. Journal of Headache and Pain 2010, 11(3):197-206.

doi:10.1186/1129-2377-14-S1-P7

Cite this article as: Kim et al:: Excessive daytime sleepiness and migraine: a population-based study. The Journal of Headache and Pain 2013 14(Suppl 1):P7. 